\title{
Magnetic Force Microscopy on Nanofibers-Limits and Possible Approaches for Randomly Oriented Nanofiber Mats
}

\author{
Andrea Ehrmann ${ }^{1, * \mathbb{D}}$ and Tomasz Blachowicz ${ }^{2} \mathbb{D}$ \\ 1 Faculty of Engineering and Mathematics, Bielefeld University of Applied Sciences, Interaktion 1, \\ 33619 Bielefeld, Germany \\ 2 Institute of Physics-Center for Science and Education, Silesian University of Technology, \\ ul. Konarskiego 22B, 44-100 Gliwice, Poland; tomasz.blachowicz@polsl.pl \\ * Correspondence: andrea.ehrmann@fh-bielefeld.de
}

Citation: Ehrmann, A.; Blachowicz,

T. Magnetic Force Microscopy on

Nanofibers-Limits and Possible

Approaches for Randomly Oriented Nanofiber Mats. Magnetochemistry 2021, 7, 143. https://doi.org/ 10.3390/magnetochemistry7110143

Academic Editor: Vladimir

I. Tsifrinovich

Received: 7 September 2021

Accepted: 21 October 2021

Published: 27 October 2021

Publisher's Note: MDPI stays neutral with regard to jurisdictional claims in published maps and institutional affiliations.

Copyright: (c) 2021 by the authors. Licensee MDPI, Basel, Switzerland. This article is an open access article distributed under the terms and conditions of the Creative Commons Attribution (CC BY) license (https:// creativecommons.org/licenses/by/ $4.0 /)$.

\begin{abstract}
Magnetic force microscopy (MFM) belongs to the methods that enable spatially resolved magnetization measurements on common thin-film samples or magnetic nanostructures. The lateral resolution can be much higher than in Kerr microscopy, another spatially resolved magnetization imaging technique, but since MFM commonly necessitates positioning a cantilever tip typically within a few nanometers from the surface, it is often more complicated than other techniques. Here, we investigate the progresses in MFM on magnetic nanofibers that can be found in the literature during the last years. While MFM measurements on magnetic nanodots or thin-film samples can often be found in the scientific literature, reports on magnetic force microscopy on single nanofibers or chaotic nanofiber mats are scarce. The aim of this review is to show which MFM investigations can be conducted on magnetic nanofibers, where the recent borders are, and which ideas can be transferred from MFM on other rough surfaces towards nanofiber mats.
\end{abstract}

Keywords: MFM; AFM; atomic force microscopy; electrospinning; nano-composite

\section{Introduction}

Magnetic force microscopy is a magnetic characterization method of samples usually with a maximum of a few ten nanometers surface roughness, which has been established more than 30 years ago and was developed further since [1-6]. It works by measuring an atomic force microscopy (AFM) image of the surface topography of a sample, followed by lifting the probe to avoid short-range van der Waals interactions between the tip and sample and instead measuring the long-range magnetic interactions (Figure 1) [5]. In addition to this simplest form of magnetic force microscopy (MFM), there are more sophisticated ones, including frequency-modulated Kelvin probe force MFM, dynamic magneto-electric force microscopy [5], phase-locked loop methods [7,8], and even measurements in different environments, e.g., in liquids, that have been shown $[9,10]$.

$\underset{\substack{\text { MFM } \\ \text { Pass }}}{\cos }$

$\underset{\text { Pass II }}{\text { MFM }}$
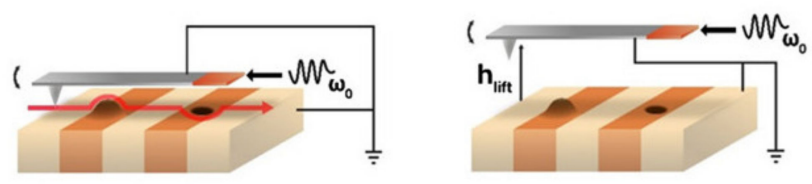

h $\uparrow$
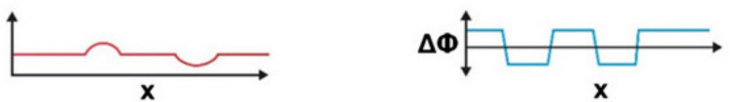

Figure 1. Standard MFM technique measuring the topography in the first pass (left) and the magnetization in the second pass after lifting the tip (right). Reprinted from [5] with permission from AIP Publishing 2019. 
MFM is usually applied to investigate magnetic domains in thin film samples or magnetic nanostructures. Hehn et al., e.g., demonstrated the reorientation of the magnetization in epitaxially grown Co thin films for thicknesses between $10 \mathrm{~nm}$ and $50 \mathrm{~nm}$, including bubble transition mechanism for larger film thicknesses and stripe domains reached by a special demagnetization process [11]. Strong variations of the magnetic domain structure were found by MFM on Ni-C thin films annealed at different temperatures [12]. Other authors investigated, e.g., Gd-Fe thin films [13] or ultrathin $\mathrm{Cu} / \mathrm{Ni} / \mathrm{Cu} / \mathrm{Si}$ films [14] by MFM. Barium ferrite single crystals were investigated from different sides, showing clear differences between the topography detected by AFM and the magnetic properties measured by MFM [15].

In addition to these smooth surfaces, highly complex domain structures were found in arrays of rectangular or elliptical permalloy nanodots by MFM [16]. Irregular plantleaf derived quantum dot clusters from graphene were investigated by MFM, showing magnetic signals only for clusters of such quantum dots [17]. An antidot array of $\mathrm{Dy}_{13} \mathrm{Fe}_{87}$ showed different morphological domains in MFM examinations [18]. Even molecular magnets have been investigated by MFM $[19,20]$.

Particularly for highly structured surfaces, the tip-sample separation is an important point which has to be taken into account. For magnetite lamella, e.g., Frandsen et al. demonstrated the influence of different separations between $100 \mathrm{~nm}$ and $1600 \mathrm{~nm}$ and not only clearly demonstrated the superposition of magnetic and topographic information for smaller separations but also the loss of magnetic information for the largest separation [21] Similarly, Al-Khafaji et al. showed the impact of tip type and separation on Nd-Fe-B crystallites [22]. Obara et al. went one step further and suggested estimating the real MFM image using observations from multiple distances [23].

These first remarks may already indicate that measuring MFM on nanostructures with a high aspect ratio, e.g., high nanodots or nanofibers, is possibly not straightforward. In a previous study, our group showed that MFM measurements on electrospun magnetic nanofiber mats with randomly arranged nanofibers in different heights are highly challenging, despite the option to follow the contour of the surface with the tip, due to the strong differences between fibers and the "empty" spaces between them, where the next fibers are positioned more than a fiber diameter below [24]. Distinguishing between magnetic and topographic signals is here even more complicated than in case of the aforementioned crystals and grains.

This is why this review investigates the recent state of MFM measurements on nanofibers in different situations and produced by different techniques, ranging from nanowire arrays to randomly distributed nanofibers as they are typically created by electrospinning.

Generally, it should be mentioned that while MFM measurements are often performed at ambient conditions [25-27], there are also measurements in vacuum and at low temperatures reported to reduce environmental noise [28-30]. In addition to these differences, measurements are sometimes performed in an external magnetic field, necessitating highcoercivity probes to avoid switching the magnetization of the cantilever in high external magnetic fields [31,32], while others magnetize the sample after removing the cantilever out of the strongest part of the magnetic field and start measuring after switching off the magnetic field again [33,34].

The manuscript is structured as follows: Starting from magnetic nanowire arrays with usually smooth surface, measurements of single nanofibers or nanowires are described before the few studies on magnetic nanofiber mats available in the literature are presented. Finally, the possibility to transfer experience from other rough surfaces to the special case of electrospun nanofiber mats or other irregular nanofiber networks is discussed.

\section{MFM on Magnetic Nanowire Arrays}

Nanowire arrays can be produced, e.g., by e-beam lithography of a photo-resist template, followed by filling the produced channels with a magnetic material by elec- 
trodeposition. Such samples can be used for magnetic recording with high density $[35,36]$ or magnetic energy storage [37-39]. Nanowire arrays produced in this manner usually have similar heights of all nanowires throughout the array, rendering MFM investigations slightly easier than on systems with larger height deviations along the surface.

Several MFM investigations can, thus, be found in the literature, which are performed on magnetic nanowire arrays. In the following text, measurements were performed under ambient conditions or environmental conditions were not mentioned in the papers. Whether they were performed in an external magnetic field or at remanence is mentioned where it is specified in the literature.

Qin et al., e.g., used a porous anodic aluminum oxide (PAO) template to prepare $\mathrm{Fe}_{0.3} \mathrm{Co}_{0.7}$ nanowires of diameters around $50 \mathrm{~nm}$ in an array [40]. They used MFM images with an undefined lift height of the very smooth surface, polished to a roughness below \pm 10 $\mathrm{nm}$, to show that each nanowire end is single-domain in the demagnetized state and can, thus, be used to represent a single bit. While the common PAO template resulted in arbitrary positioning of the nanowires, the same group also used a highly ordered anodic alumina oxide (AAO) membrane with similar diameters to grow Co nanowires and used MFM on the polished composite surface to investigate the magnetic states of the single nanowires at saturation and at remanence [41]. Similarly, Ni nanowires in a hexagonal arrangement were investigated by MFM in order to study the role of magnetostatic interaction in the array, here investigating the sample at different remanent states after in situ application of magnetic fields up to $500 \mathrm{Oe}$ [42]. This fact was also taken into account by Yuan et al. who calculated the reversal field distribution with and without the correction of magnetostatic fields according to a set of MFM images, taken at different external magnetic fields, in comparison with isothermal remanent magnetization and DC demagnetized magnetization curves [43].

Even for highly polished surfaces, MFM may become difficult due to insufficient lateral resolution. Asenjo et al. discussed the possibility of evaluating remanent magnetization of a nanowire array from MFM images, taken after in situ application of a magnetic field [44]. They prepared Ni polycrystalline wires with diameters around $35 \mathrm{~nm}$ and length 1000 $\mathrm{nm}$ by electrodeposition into the nanopores of an alumina membrane template. For MFM investigations, they used a standard MFM tip with $50 \mathrm{~nm}$ Co coating, i.e., broader than the wire diameter. By simulations, they showed the influence of the MFM tip diameter, as depicted in Figure 2, which has to be taken into account in case of quantitative MFM measurements performed with thicker tips.

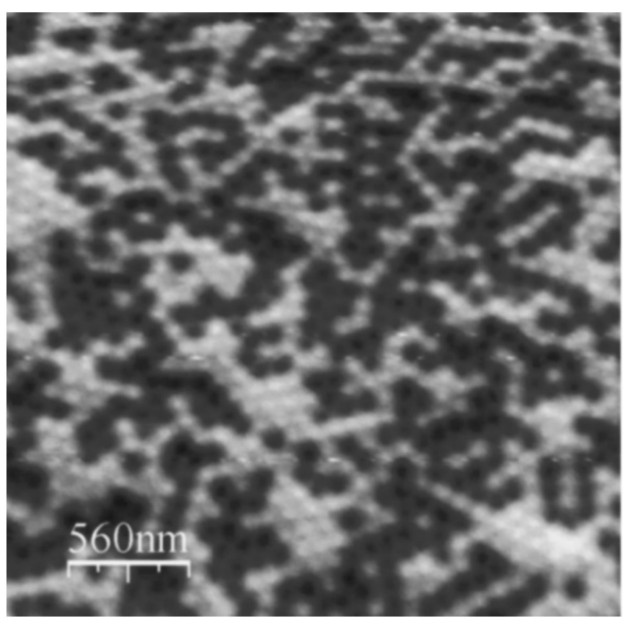

(a)

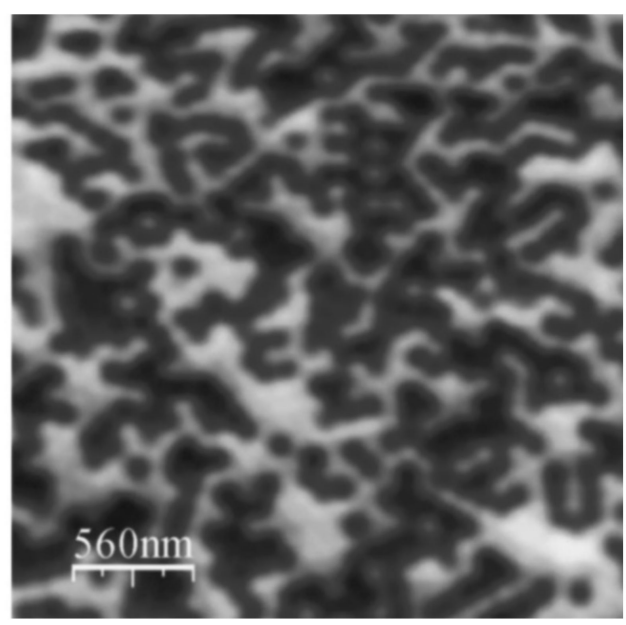

(b)

Figure 2. (a) MFM image of a Ni nanowire array at remanence measured with the aforementioned tip diameter; (b) simulated MFM image of the same MFM data for an assumed tip with a magnetic domain size of $140 \mathrm{~nm}$. Image size: $2.8 \mu \mathrm{m} \times 2.8 \mu \mathrm{m}$. Reprinted from [44], with permission from AIP. 
Using a similar nickel nanowire array with hexagonal symmetry, Nielsch et al. investigated the possibility of fully magnetizing an area of the previously demagnetized sample by a strongly magnetized MFM tip in addition to the external magnetic field [45]. They found that both fields taken together were sufficient to overcome the average switching field of the nanowires so that $93 \%$ of the nickel nanowires were magnetized in the desired direction in the magnetized region of the sample.

During the last years, more special magnetic nanowire arrays were prepared and investigated by MFM, such as spin-ice structures or other lithographically produced ones. May et al. managed to produce a 3D nanowire lattice with magnetic frustration [46]. The permalloy nanowires in this system had diameters of $160 \mathrm{~nm}$ and showed magnetization reversal by domain wall nucleation and propagation. Large spaces can be found between them, as in the aforementioned electrospun nanofiber mats, with the difference that the latter are not regularly arranged. The authors used commercial low-moment MFM tips, magnetized parallel or antiparallel to the tip axis by a $0.5 \mathrm{~T}$ permanent magnet, and a lift height of $100 \mathrm{~nm}$ after careful optimization of the feedback setting with respect to the sample's topography. During sample magnetization with an electromagnet in situ, the MFM tip was raised by several millimeters in order to avoid modifications of the tip magnetization. Two MFM images gained with the tip magnetized in opposite directions are depicted in Figure 3. Despite the aforementioned difference between the here measured 3D lattice-like sample and a nanofiber mat with randomly oriented fibers in different heights, the order of magnitude of the tip height may be suitable for MFM measurements on nanofiber mats too, as the nanofibers themselves are in a similar diameter range as the nanowires investigated here. However, it must be mentioned that the understanding of the magnetic structure is, in the case of a regular lattice, supported by the morphology, which is not the case in an irregular structure.

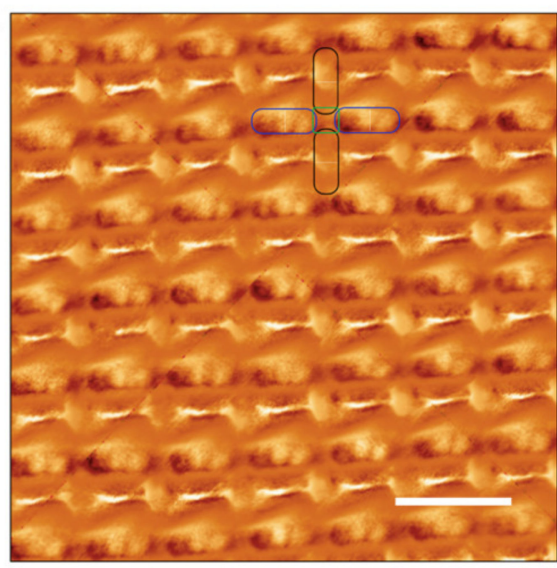

b

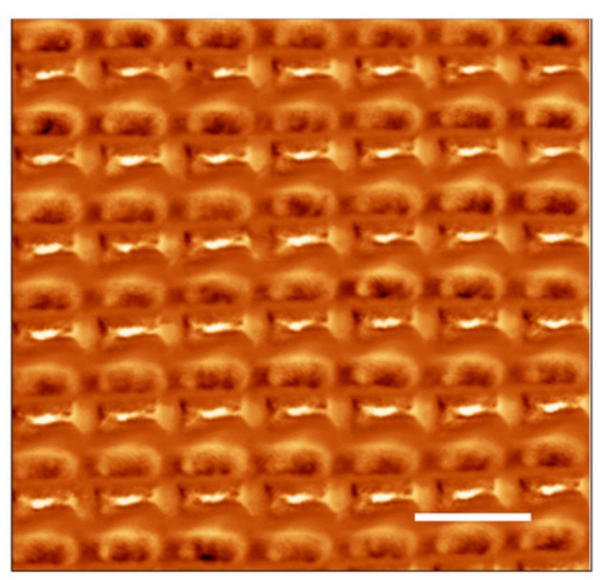

Figure 3. (a,b) MFM images of Py nanostructured lattice with opposite tip magnetizations. Scale bars are $2 \mu \mathrm{m}$ long. Reprinted from [46] and originally published under a CC-BY license.

In a more recent paper, the authors mention measuring three uppermost lattice layers, made possible by careful optimization of the feedback settings, again by lifting the MFM tip several millimeters above scanning height during the application of an external magnetic field to the sample [47]. Here, they also point out that the MFM phase measures the stray field gradient $\mathrm{d}^{2} \mathrm{~Hz} / \mathrm{dz}^{2}$ and is, thus, ideal for visualizing magnetization transport across the surface [48].

Other wire-based structures are again 2D structures, which will-together with single nanowires-be described in the next section.

\section{MFM on Single Magnetic Nanowires and Nanofibers}

The aforementioned spin-ice structures belong to the often examined 2D structures consisting of in-plane oriented nanowires or, more often, nano-lines typically attained 
from lithographic processes. These structures are often investigated by MFM since the spatially resolved magnetization is of high interest [49-53]. However, they are in most cases two-dimensional and, thus, not within the scope of this paper, which aims at discussing possibilities for investigating three-dimensional nanofibrous structures.

For single magnetic nanowires or nanofibers, placed on a sample holder and, thus, investigated along their entire length (instead of from top, as in the previously mentioned nanowires arrays), it must be firstly mentioned that due to the MFM being sensitive to field gradients, the interpretation of MFM images is sometimes not straightforward. Berganza et al., e.g., explained MFM images of multisegmented nanowires from CoNi and Ni by a periodic multivortex structure with opposite vortex chiralities or a single vortex configuration, as depicted in Figure 4 [54]. The group used an amplitude modulation mode with phase-locked loop enabled and home-made Co MFM probes as well as MagneticMulti75-G (Budget Sensors) with CoCr coating [54]. The same setup was reported by Bran et al. who reported an oscillation amplitude of the cantilever of 10-15 nm and a typical lift height of $40 \mathrm{~nm}$ for investigations of metastable transverse and vortex domains in cylindrical nanowires, measured at remanence or under in situ applied magnetic fields [55].

(a)

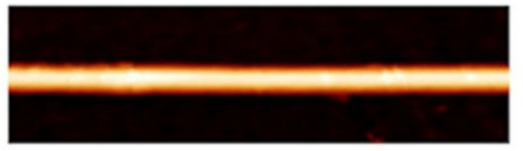

(b)

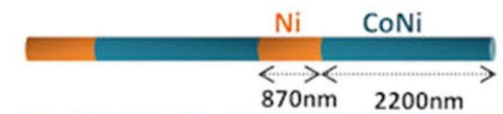

(c)

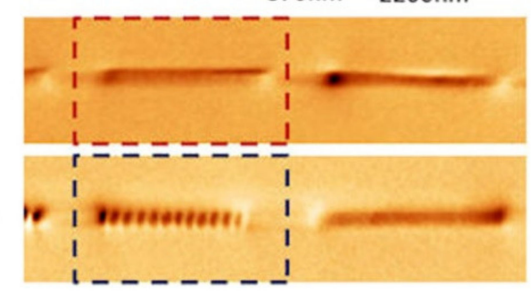

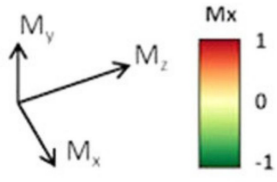

Magnetic configuration

(e)

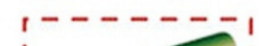

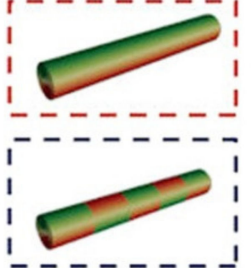

Figure 4. (a) Topography, (b) geometry sketch, and (c,d) MFM images of different nanowires. In (c), the segment in the red square shows a uniform magnetization, while in (d) a multidomain structure is displayed. Figures (e,f) schematically show the expected magnetization configurations corresponding to (c,d) MFM images, respectively. Reprinted from [54] and originally published under a CC-BY license.

A more complicated image series taken by Askey et al. working with Ni nanowires produced by two-photon lithography [56]. During magnetization reversal from remanence, they found complex spin structures including vortex and antivortex pairs and generally a spiraling domain along the external magnetic field direction. They reported using a lift height of $80 \mathrm{~nm}$ and a low moment $\left(5 \times 10^{-14} \mathrm{emu}\right)$ tip, measuring in an applied field between $0 \mathrm{mT}$ and $10 \mathrm{mT}$.

Another important effect that has to be taken into account in the interpretation of MFM measurements is the stray field of the tip [57]. Nasirpouri et al. investigated tri-segmented nickel nanowires with alternating thicker and thinner sections of different lengths by MFM with a commercial CoCr standard tip and found strong contrast due to accumulated magnetic charges at the ends of the nanowires, as typical for axial magnetization, as well as at the points where the nanowire diameter was modulated [58]. They used micromagnetic simulations to prove that magnetization reversal began with domain wall nucleation in a thick segment and propagation towards this diameter modulation point and that the interpretation of their MFM images was not misled by possible stray fields of the tip.

Core-León et al. investigated in detail the effect of tip shape and orientation of the magnetic field when magnetizing the tip on the residual magnetization and, thus, the stray fields around the tip and revealed a doubled MFM phase contrast for special V- 
shaped samples [59]. Moreover, they showed that the strong shape anisotropy in their custom-made tips was suitable for measuring MFM at large fields up to $80 \mathrm{mT}$ without the danger of switching the magnetization of the tip. Finally, both in-plane and out-of-plane magnetization could be measured with their tips, as depicted in Figure 5 [59].

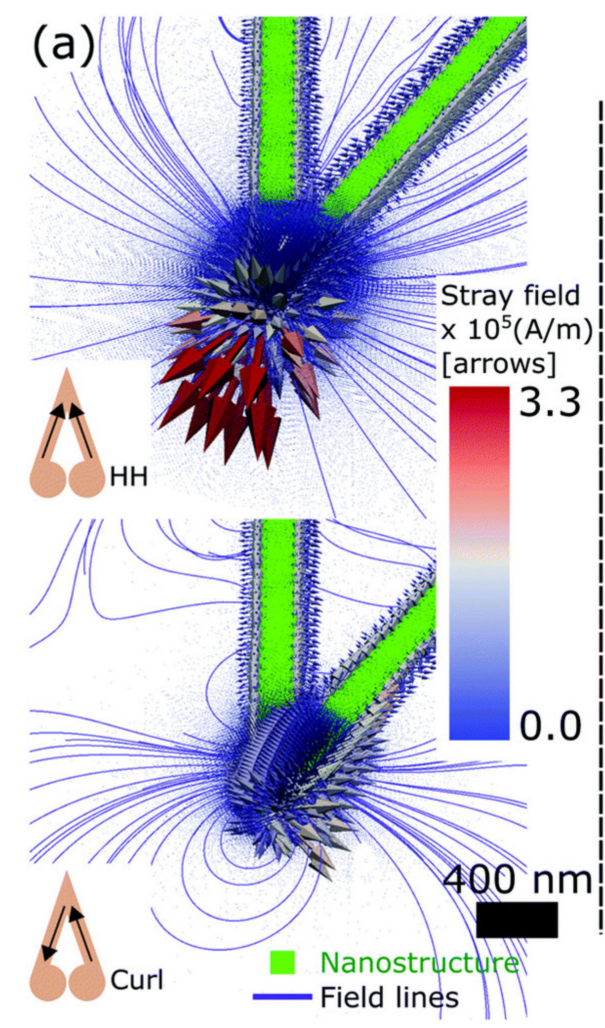

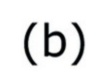

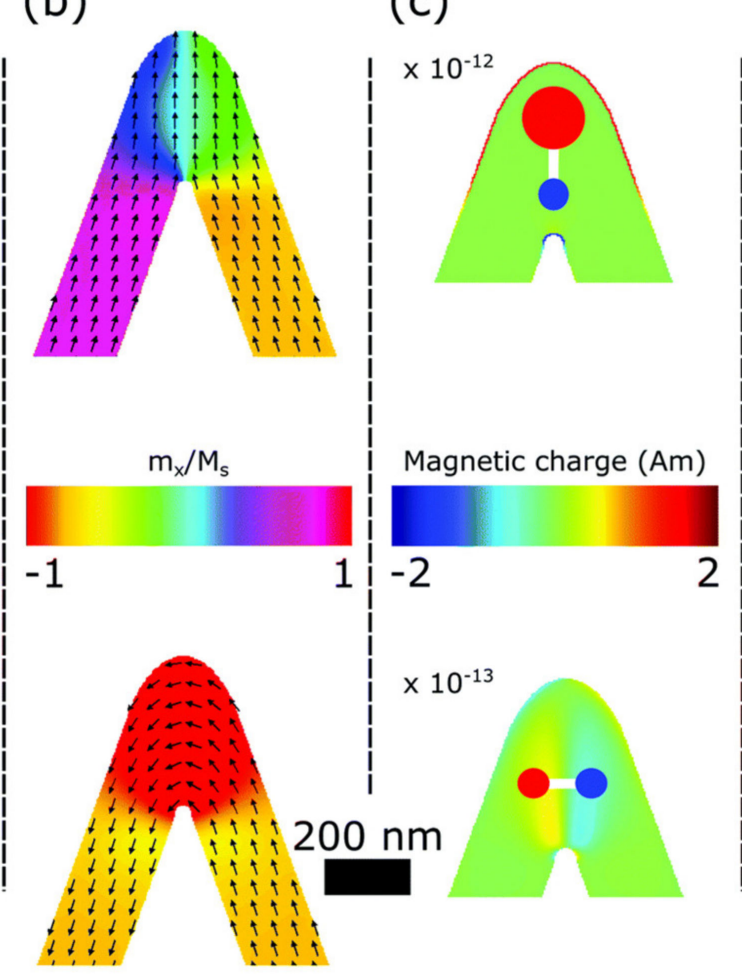

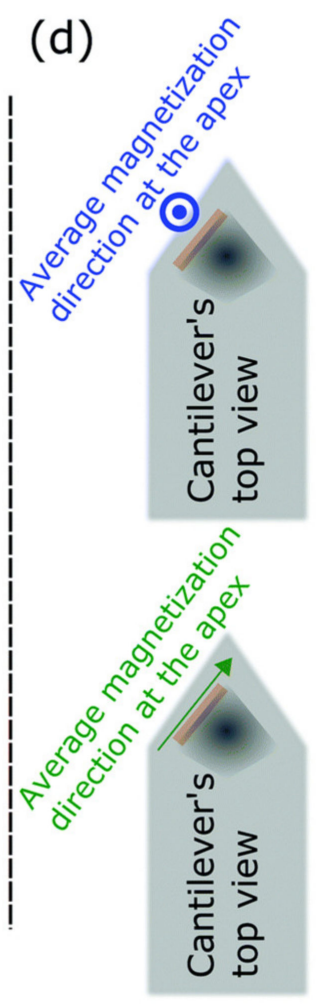

Figure 5. Numerically simulated magnetization and stray fields of suggested MFM probe. (a) Stray field created by the V-shaped magnetic nanostructure when magnetization is either in head-to-head state (top row) or curl state (bottom row). Corresponding images for (b) magnetization, (c) magnetic charge distribution, and (d) the direction of the stray field during MFM measurements. Reprinted from [59] and originally published under a CC-BY-NC license.

Generally, thin magnetic nanowires often show magnetization orientation along the nanowire axis so that only a magnetic contrast is visible in MFM at the end, as measured in remanence after applying an external magnetic field pulse during which the tip was lifted away from the field by $12 \mu \mathrm{m}$ [60]. This magnetization, however, can be measured by a laterally magnetized MFM tip [61], as also suggested in [59]. On the other hand, there are other diverse reports of more interesting magnetic structures, either in the form of domain walls during magnetization reversal, measured at different magnetic fields [62], or as multi-domain structure at remanence [63-65].

During the last years, the focus of MFM investigations of single magnetic nanowires shifted to nanowires with modulated diameters, as already mentioned before [66]. Bochmann et al. reported domain walls in multi-segment nickel-cobalt nanowires along the segment borders as well as close to them without providing further information about experimental conditions [67]. In a previous investigation, the group prepared $\mathrm{NiCo} / \mathrm{Cu}$ nanowires of diameter $40 \mathrm{~nm}$ and could nicely demonstrate small single-domain bits separated by the nonmagnetic $\mathrm{Cu}$ segments by MFM at remanence, as depicted in Figure 6 [68]. Here, MESP tips (Bruker, Billerica, USA) with cobalt chromium coating were used. 

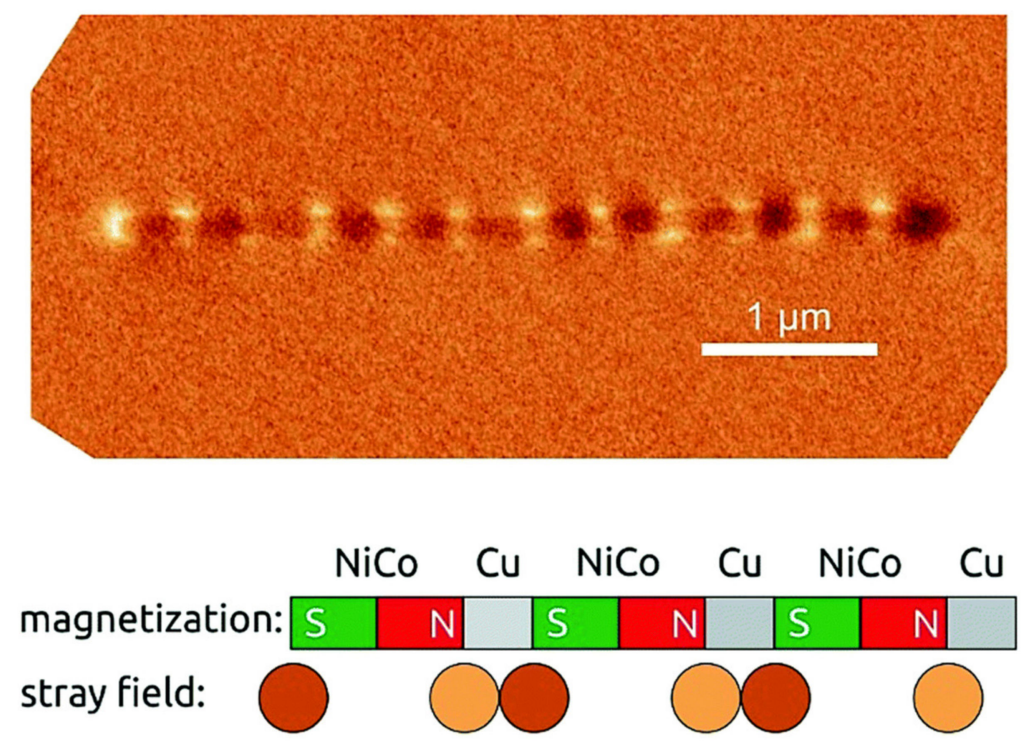

Figure 6. MFM images of an isolated $\mathrm{Ni}_{60} \mathrm{Co}_{40} / \mathrm{Cu}$ wire of diameter $40 \mathrm{~nm}$ (top); scheme of how the pattern observed in MFM originates from the alternation of magnetized and non-magnetic segments (bottom). Reprinted from [68] and originally published under a CC-BY license.

A more complex T-shaped magnetic structure was most recently suggested as possible magnetic storage element with experimental evidence of four stable magnetic states [69] and earlier by micromagnetic simulations [70]. In the experimental study [69], MFM images were used to depict the four different possible states visible by dark and bright contrast at the ends of the wires as well as in the crossing point. Here again, MESP tips with $\mathrm{CoCr}$ coating and a coercivity of $65 \mathrm{mT}$ (Bruker) were used with a double-pass scanning method in tapping mode and a lift height of $60 \mathrm{~nm}$ with contour following option and measuring at remanence after the ex situ application of an external magnetic field. The authors mentioned that in their samples, prepared from Co with high magnetic moment, the electrostatic interaction between tip and sample can be neglected, which is not the case for samples with low magnetic moment, e.g., magnetic oxide nanowires. In order to solve this problem in case of magnetic oxide nanowires, Jaafar et al. suggested additional Kelvin probe force microscopy to enable distinguishing between magnetic and electrostatic interaction [71]. In their experiments, they used MFM probes with an in-plane coercive field larger than the in situ applied external magnetic fields during measurements, performed at lift heights of $25-30 \mathrm{~nm}$.

In other studies of single magnetic nanowires, a single-pass mode was used instead of a double-pass mode, using one of the aforementioned probes and typically also lift heights of some ten nanometers, while an in situ magnetic field of up to $\pm 16 \mathrm{mT}$ was applied [72]. Generally, lift height, double-pass or single-pass mode, or even the cantilever are not always provided in papers reporting MFM on magnetic nanowires; however, where reported, there is a certain agreement on lift heights in the range of several ten to around hundred nanometers, and MESP tips (with Co/Cr coating) and MagneticMulti75-G (identical with Multi75M-G) are often applied in these studies [73]. It should be mentioned that the tip height is essential in these measurements, as Dai et al. convincingly demonstrated in their introduction of a new MFM system and as depicted in Figure 7 [74]. Here, it becomes quite clear that the lift height must be as small as possible in order to reach a sufficient phase contrast, while rough surfaces necessitate using larger lift heights. This renders MFM investigations of rough surfaces, especially with respect to chaotic nanofiber mats produced by electrospinning, quite complicated, as the next sections will show. 

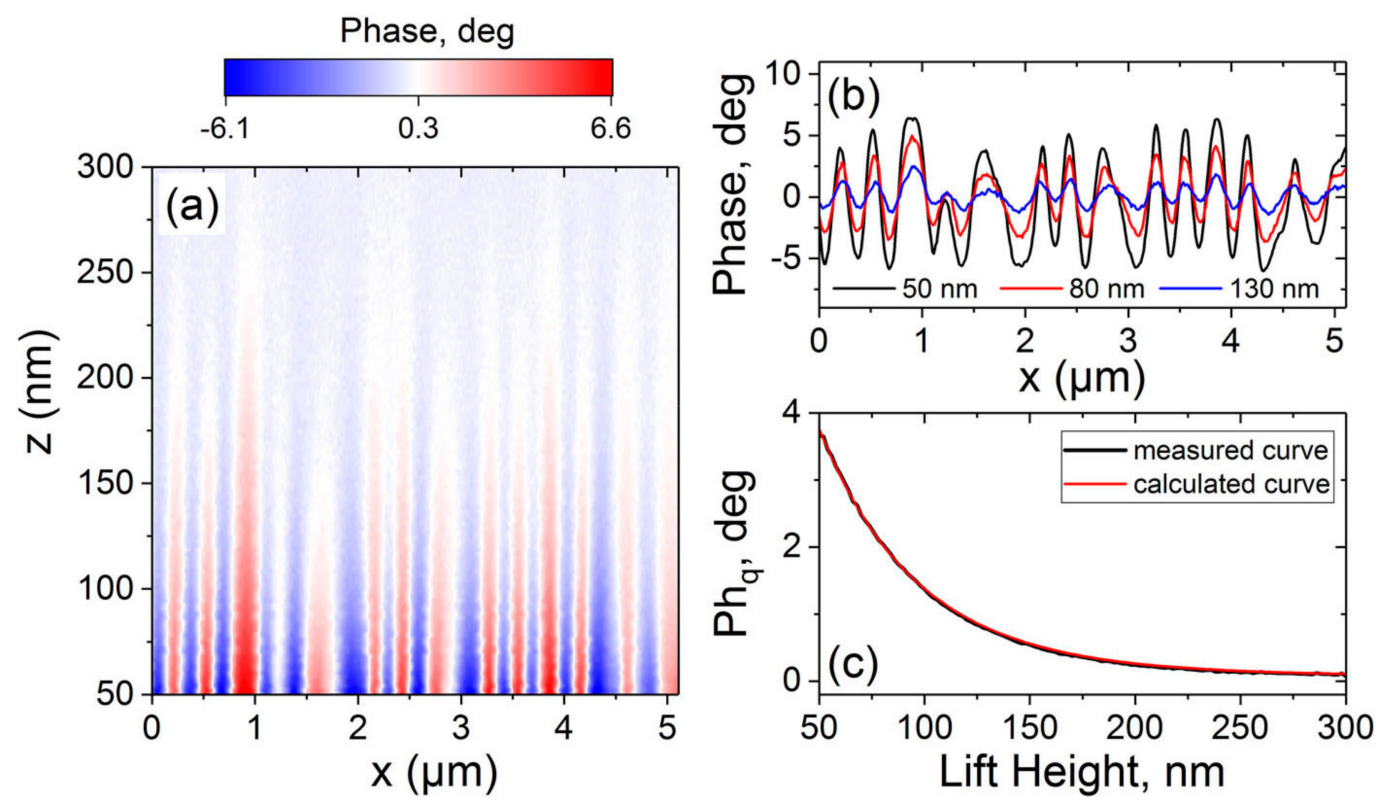

Figure 7. (a) An MFM phase image measured in the MFMZ mode when the lift height $\mathrm{H}$ is changed from $50 \mathrm{~nm}$ to $300 \mathrm{~nm}$; (b) cross-sectional phase profiles measured at the lift height of $50 \mathrm{~nm}, 80 \mathrm{~nm}$, and $130 \mathrm{~nm}$, respectively; (c) the relationships between the measured phase signal strength (black) and calculated signal strength (red) vs. lift height. Reprinted from [74] and originally published under a CC-BY license.

\section{MFM on Magnetic Nanofiber Mats}

One study working on electrospun magnetic nanofibers was published by Choopani et al. who prepared $\mathrm{Y}_{3} \mathrm{Fe}_{5} \mathrm{O}_{12} @ \mathrm{Na}_{0.5} \mathrm{~K}_{0.5} \mathrm{NbO}_{3}$ core-shell nanofibers by coaxial electrospinning [75]. The paper, however, shows only MFM images of a single nanofiber taken out of the complete nanofiber mat and taken under conditions that are not further defined.

Another example of freestanding nanofibers is shown by Chearkasov et al., who grew layered $\mathrm{Ni} / \mathrm{Cu}$ nanowires in a highly three-dimensional structure [76]. However, only a single nanofiber was investigated here again at remanence and in an external magnetic field of $16 \mathrm{mT}$, placed flat on a substrate. Arias et al. used a very low scanning area of $200 \mathrm{~nm}$ width so that they could even measure MFM completely on top of a single $\mathrm{ZnFe}_{2} \mathrm{O}_{4} / \gamma-\mathrm{Fe}_{2} \mathrm{O}_{3}$ electrospun nanofiber [77].

Single nanofibers [78] and crossing points of two nanofibers [79] were investigated by Prashanthi et al. in the MFM lift-mode with phase detection, and they used sol-gel based electrospinning to prepare $\mathrm{BiFeO}_{3}$ nanofibers. Here, no further information about tip or lift height was provided.

Baranowska-Korczyc et al. managed taking MFM images of an ensemble of electrospun Fe doped $\mathrm{ZnO}$ nanofibers on an even surface [80], as depicted in Figure 8. While it can be assumed that most of the contrast between the fibers in Figure $8 \mathrm{~b}$ and the substrate result from morphological contrast, there are also structures visible on top of the nanofibers that are stronger in the MFM images than in the AFM image (Figure 8a) and can, thus, be attributed to magnetic contrast. The authors used an OTESPA $160 \mu \mathrm{m}$ tip and a lift height of $150 \mathrm{~nm}$, i.e., larger than the diameter of the thickest fibers.

However, most other papers showing MFM images on electrospun nanofibers deal with single nanofibers taken out of the mat and not with the full nanofiber mat [81-86]. Lift heights were, e.g., reported in the range of 50-100 nm [81], while hard-magnetic tips (coercivity $300 \mathrm{Oe}$ ) [81] or silicon nitride tip $[82,86]$ were used to detect signals from the single fibers mounted e.g., by setting them in a polymer glue [81]. In an aforementioned paper of our group demonstrating, to our knowledge, the first attempts to measure MFM on complete nanofiber mats at remanence [24], the problems mentioned before regarding the optimization of the lift height were also found, resulting in the problem that at too small lift heights, the nanofiber morphology was still visible despite the use of contour following 
mode and double-pass mode, while at too large lift heights, the magnetic information could not be properly visualized.
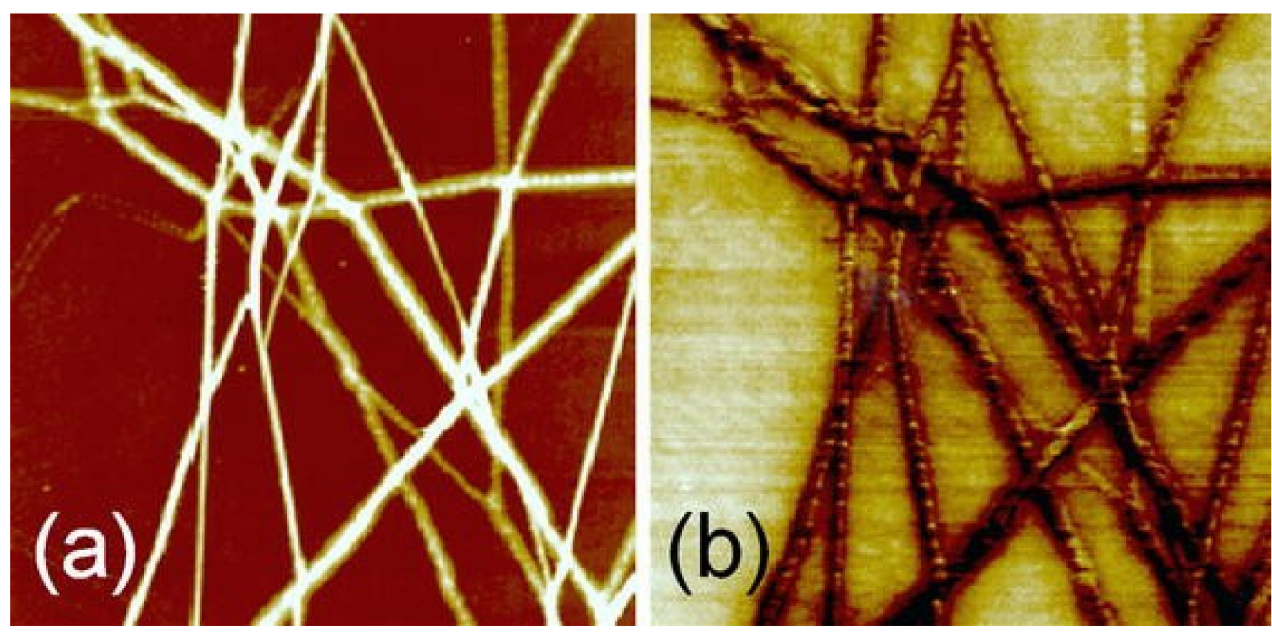

Figure 8. (a) AFM and (b) MFM images of Fe doped ZnO nanofibers. The scanned areas of both images are $30 \mu \mathrm{m} \times 30 \mu \mathrm{m}$. Reprinted from [80] and originally published under a CC-BY-NC license.

Due to this lack of sufficient results regarding MFM measurements on electrospun nanofiber mats and other chaotic nanofiber arrangements, the next section discusses approaches reported in the literature for MFM measurements on other rough surfaces and what can be learnt from them.

\section{MFM on Rough Surfaces-What Can Be Transferred to Nanofiber Mats}

Naturally, electrospun nanofiber mats are not the only samples with high surface roughness. Saito et al. and Cao et al. reported MFM measurements on an Sr ferrite sintered magnet with an extremely high roughness of approximately $1 \mu \mathrm{m}$ [87-89]. This is a similar order of magnitude that can be estimated in typical electrospun nanofiber mats in which nanofibers, typically with diameters of some hundred nanometers, are positioned on top of each other with large pores through which lower layers are accessible. Thus, they suggested an advanced MFM technique using the frequency modulation of a cantilever oscillation by applying an AC magnetic field to an oscillating MFM tip and showed that the frequency-demodulated signals of the cantilever oscillation, more exactly the side-band spectra appearing on both sides of the base-band spectrum of the cantilever oscillation, could be used to calculate the amplitude and polarity of the AC magnetic field gradient. In this case, the external AC magnetic field did not influence the topography measurement. Their calculation showed that the second derivative of the out-of-plane stray field could be measured by the side-band frequency without crosstalk with the signal due to surface morphology. The difference between MFM images with this technique using an FeCo$\mathrm{GdO}_{\mathrm{x}}$ superparamagnetic tip, called A-MFM, and conventional MFM images, measured by a FePt hard-magnetic tip, is depicted in Figure 9 [89]. Obviously, the topography, which seems to have a large impact in the conventional MFM image (Figure 9f), does not play a key role in the A-AFM images showing amplitude R and phase, respectively (Figure 9c,d). This technique could, thus, be very supportive in imaging magnetic nanofiber mats. 

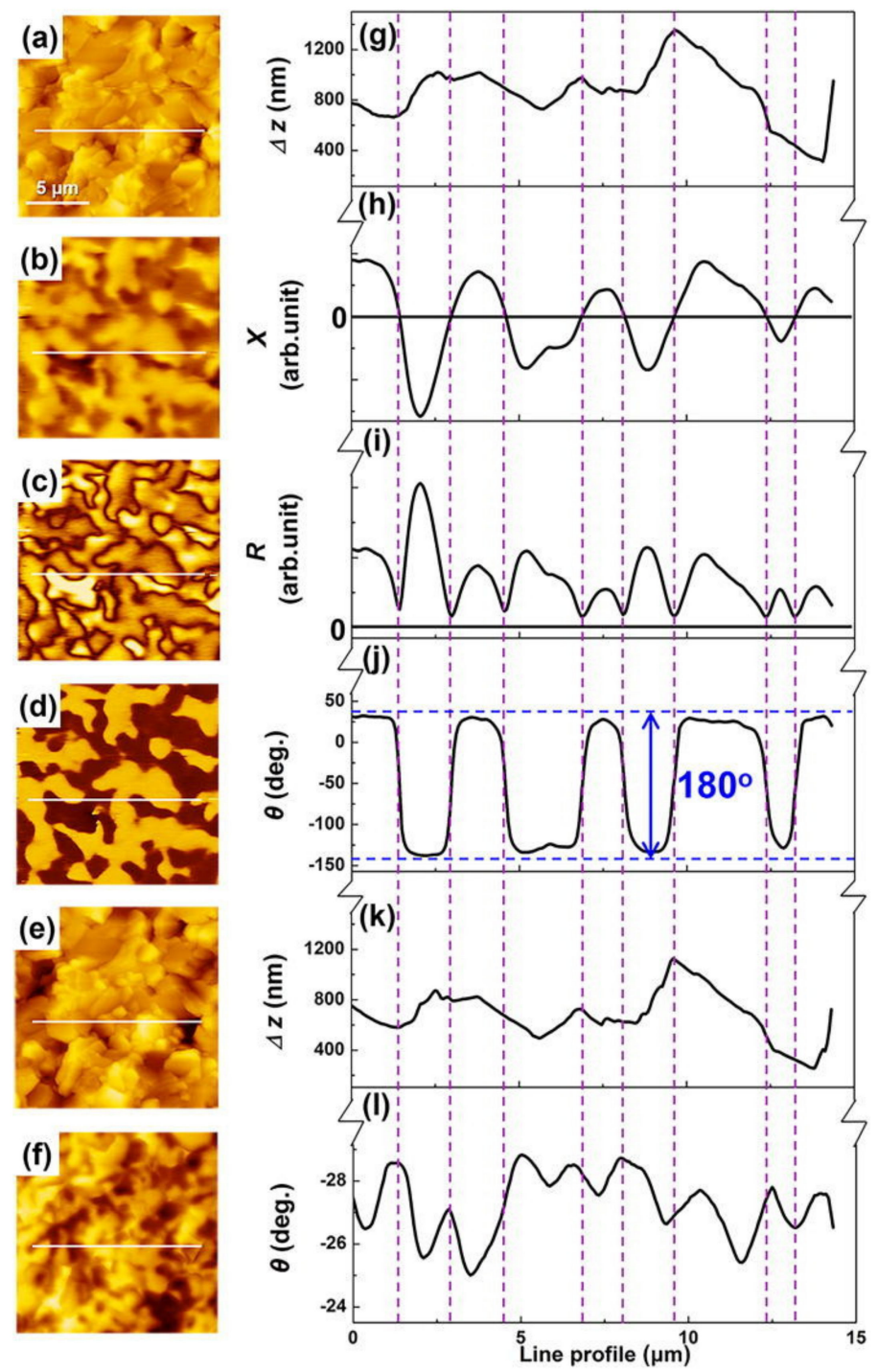

Figure 9. (a) A-MFM topographic image, (b) A-MFM in-phase X image (in-phase output of lock-in amplifier), and (c) A-MFM amplitude R image (amplitude output of lock-in); (d) A-MFM phase image of $\mathrm{SrF}$ measured by $\mathrm{FeCo}-\mathrm{GdO}_{\mathrm{x}}$ superparamagnetic tip; (e) topographic image and (f) phase image of the conventional MFM of the SrF measured by FePt hard-magnetic tip and their corresponding line profiles (g-1). Reprinted from [89] and with permission from AIP Publishing 2018.

Most papers describing MFM measurements on rough surfaces, however, have to confront much smaller roughness typically in the range of some ten nanometers up to slightly above $100 \mathrm{~nm}$ [90-92], which is approximately one order of magnitude below the "roughness" of typical electrospun nanofiber mats. Even for roughness in the range of $10 \mathrm{~nm}$, Jena et al. found only a very small magnetic contrast that could not be reliably separated from topological signals [93]. For Ni films on self-assembled polystyrene beads with a roughness of approximately $60 \mathrm{~nm}$, measured with pyramidal silicon tips with Co/Cr coating, Sharma et al. reported using a lift height of $120 \mathrm{~nm}$, i.e., twice the roughness, in order to avoid crosstalk with the topographic signal [94], which would be impossible for deviations in the height of neighboring nanofibers in the range of several hundred nanometers as compared with a study of Nenadovic et al. who observed maximum lift heights of $100 \mathrm{~nm}$ for Co and $\mathrm{Ni}$ thin films for delivering a reliable image of the magnetization [95]. While few papers report slightly larger lift heights for rough surfaces [80], apparently it is not possible to increase this value much further, as already shown in Figure 7 [74]. On the other hand, it must be mentioned that the 3D systems reported in [46-48], with an approximate distance 
between the upper two layer investigated by MFM of about $0.8-0.9 \mu \mathrm{m}$, was measured with a lift height of only $100 \mathrm{~nm}$ [48].

In addition to using sophisticated methods such as the A-MFM described in [87-89], this example shows that measuring MFM on surfaces with high roughness is possible even with common equipment, suggesting transferring these approaches to nanofiber mats. The next approach for investigating electrospun magnetic nanofiber mats should, thus, be based on partially oriented nanofiber mats, as they can be produced by electrospinning on fast rotating cylinders such as counter electrodes, they can be utilized to start parameter optimization from such samples between ordered and chaotic structures, they can be used for attaining deeper understanding, and finally for finding the optimum tip, lift height and AFM parameters for measuring even more random nanofiber mats.

\section{Conclusions}

This paper discusses the possibility of investigating chaotically distributed magnetic nanofibers, e.g., those produced by electrospinning, by magnetic force microscopy. While MFM investigations of regular magnetic nanofiber arrays with surface heights differing only slightly can often be found in the literature and MFM measurements on single nanofibers, positioned flat on a substrate, are also regularly performed, investigations of many nanofibers in one MFM image or even an entire nanofiber mat are as scarce as examinations of 3D lattice structures. However, both chaotic and regular wire-based 3D structures were found. While one of the groups underlined the importance of carefully optimizing the AFM parameters before measuring MFM, another group increased the tip height to a level where topographic and magnetic signals were visible simultaneously, and again another group invented new technology in order to fully cancel the topographic signal and to allow for high magnetic contrast measurements even on a surface with roughness in the range of $1 \mu \mathrm{m}$.

These examples show that measuring MFM on chaotic nanofiber mats must be possible although it has not yet been reported. According to the literature, the easiest method to approach this goal begins with investigations of partially oriented nanofiber mats, as they can be produced, e.g., by electrospinning on a fast rotating cylinder, and extending this first step further towards more chaotic and correspondingly rougher surfaces.

Author Contributions: Conceptualization, A.E. and T.B.; methodology, A.E. and T.B.; formal analysis, A.E. and T.B.; writing—original draft preparation, A.E. and T.B.; writing—review and editing, T.B. and A.E.; visualization, A.E. and T.B. All authors have read and agreed to the published version of the manuscript.

Funding: This research received no external funding.

Institutional Review Board Statement: Not applicable.

Informed Consent Statement: Not applicable.

Data Availability Statement: No new data were generated in this review paper.

Conflicts of Interest: The authors declare no conflict of interest.

\section{References}

1. Sáenz, J.J.; García, N. Observation of magnetic forces by the atomic force microscope. J. Appl. Phys. 1987, 62, 4293. [CrossRef]

2. Grütter, P.; Mamin, H.J.; Rugar, D. Magnetic force microscopy (MFM). In Scanning Tunneling Microscopy II; Wiesendanger, R., Güntherodt, H.J., Eds.; Springer: Berlin/Heidelberg, Germany, 1992; pp. 151-207.

3. Hug, H.J.; Stiefel, B.; van Schendel, P.J.A.; Moser, A.; Hofer, R.; Martin, S.; Güntherodt, H.-J. Quantitative magnetic force microscopy on perpendicularly magnetized samples. J. Appl. Phys. 1998, 83, 5609. [CrossRef]

4. Koblischka, M.R.; Hartmann, U. Recent advances in magnetic force microscopy. Ultramicroscopy 2003, 97, 103-112. [CrossRef]

5. Kazakova, O.; Puttock, R.; Barton, C.; Corte-León, H.; Jaafar, M.; Neu, V.; Asenjo, A. Frontiers of magnetic force microscopy. J. Appl. Phys. 2019, 125, 060901. [CrossRef]

6. Abelmann, L. Magnetic force microscopy. In Encyclopedia of Spectroscopy and Spectrometry, 3rd ed.; Academic Press: Oxford, UK, 2017; pp. 675-684. 
7. Katsuki, A.; Matsushima, M. Current-feedback magnetic multivibrator with feedback-controlled frequency compensation circuit using phase-locked loop. In Proceedings of the 25th International Telecommunications Energy Conference, Yokohama, Japan, 23 October 2003; pp. 352-357.

8. Schwenk, J.; Marioni, M.; Romer, S.; Joshi, N.R.; Hug, H.J. Non-contact bimodal magnetic force microscopy. Appl. Phys. Lett. 2013, 104, 112412. [CrossRef]

9. Jaafar, M.; Pablo-Navarro, J.; Berganza, E.; Ares, P.; Magén, C.; Masseboeuf, A.; Gatel, C.; Snoeck, E.; Gómez-Herrero, J.; María de Teresa, J.; et al. Customized MFM probes based on magnetic nanorods. Nanoscale 2020, 18, 10090-10097. [CrossRef]

10. Ares, P.; Jaafar, M.; Gil, A.; Gómez-Herero, J.; Asenjo, A. Magnetic force microscopy in liquids. Small 2015, 11, 4731-4736. [CrossRef] [PubMed]

11. Hehn, M.; Padovani, S.; Ounadjela, K.; Bucher, J.P. Nanoscale magnetic domain structures in epitaxial cobalt films. Phys. Rev. B 1996, 54, 3428-3433. [CrossRef]

12. Pandey, M.K.; Kar, A.K. Effect of annealing temperature on the magnetic domain structure and surface mechanical properties of Ni-C composite thin films: Magnetic and lateral force microscopy, and force-distance spectroscopy. Mater. Lett. 2021, $301,130295$. [CrossRef]

13. Talapatra, A.; Arout Chelvane, J.; Mohanty, J. Microscopic understanding of domain formation in Gd-Fe thin films. In AIP Conference Proceedings; AIP Publishing LLC: Melville, NY, USA, 2017; Volume 1832, p. 130044.

14. Hug, H.; Stiefel, B.; Moser, A.; Parashikov, I.; Klicznik, A.; Lipp, D.; Güntherodt, H.-J.; Bochi, G.; Paul, D.I.; O’Handley, R.C. Magnetic domain structure in ultrathin $\mathrm{Cu} / \mathrm{Ni} / \mathrm{Cu} / \mathrm{Si}(001)$ films. J. Appl. Phys. 1996, 79, 5609. [CrossRef]

15. Jali, J.V.; Hong, Y.-K.; Abo, G.S.; Bae, S.; Lee, J.-J.; Park, J.-H.; Choi, B.C.; Kim, S.-G. MFM studies of magnetic domain patterns in bulk barium ferrite $\left(\mathrm{BaFe}_{12} \mathrm{O}_{19}\right)$ single crystals. J. Magn. Magn. Mater. 2011, 323, 2627-2631. [CrossRef]

16. Liou, S.H.; Sabiryanov, R.F.; Jaswal, S.S.; Wu, J.C.; Yao, Y.D. Magnetic domain patterns of rectangular and elliptic arrays of small permalloy elements. J. Magn. Magn. Mater. 2001, 226-230, 1270-1272. [CrossRef]

17. Chuang, C.S.; Matsunaga, M.; Wang, T.-H.; Roy, P.; Ravindranath, R.; Ananthula, M.; Aoki, N. Investigation of plant leaf-derived graphene quantum dot clusters via magnetic force microscopy. Nanotechnology 2021, 32, 245704. [CrossRef] [PubMed]

18. Salaheldeen, M.; Vega, V.; Ibabe, A.; Jaafar, M.; Asenjo, A.; Fernandez, A.; Prida, V.M. Tailoring of perpendicular magnetic anisotropy in $\mathrm{Dy}_{13} \mathrm{Fe}_{87}$ thin films with hexagonal antidote lattice structure. Nanomaterials 2018, 8, 227. [CrossRef]

19. Serri, M.; Mannin, M.; Poggini, L.; Vélez-Fort, E.; Cortigiani, B.; Sainctavit, P.; Rovai, D.; Caneschi, A.; Sessoli, R. Low-temperature magnetic force microscopy on single molecule magnet-based microarrays. Nano Lett. 2017, 17, 1899-1905. [CrossRef]

20. Blachowicz, T.; Ehrmann, A. New materials and effects in molecular nanomagnets. Appl. Sci. 2021, 11, 7510. [CrossRef]

21. Frandsen, C.; Stipp, S.L.S.; McEnroe, S.A.; Madsen, M.B.; Knudsen, J.M. Magnetic domain structures and stray fields of individual elongated magnetite grains revealed by magnetic force microscopy (MFM). Phys. Earth Planet. Inter. 2004, 141, 121-129. [CrossRef]

22. Al-Khafaji, M.A.; Rainforth, W.M.; Gibbs, M.R.J.; Bishop, J.E.L.; Davies, H.A. The effect of tip type and scan height on magnetic domain images obtained by MFM. IEEE Trans. Magn. 1996, 32, 4138-4140. [CrossRef]

23. Obara, G.; Sakurai, T.; Ono, O. Magnetic domain observations of ferrite sintered magnets using MFM images observed from multiple distances and image processing. IEEE Trans. Magn. 2019, 55, 1-4. [CrossRef]

24. Weiss, R.; Ehrmann, A. Preliminary report on MFM measurements on magnetic nanofiber mats. Commun. Dev. Assem. Text. Prod. 2021, 2,1-7.

25. Amos, N.; Ikkawi, R.; Haddon, R.; Litvinov, D.; Khizroev, S. Controlling multidomain states to enable sub-10-nm magnetic force microscopy. Appl. Phys. Lett. 2006, 93, 203116. [CrossRef]

26. Nocera, T.M.; Chen, J.; Murray, C.B.; Agarwal, G.J. Magnetic anisotropy considerations in magnetic force microscopy studies of single superparamagnetic nanoparticles. Nanotechnology 2012, 23, 495704. [CrossRef]

27. Makarova, M.V.; Akaishi, Y.; Ikarashi, T.; Rao, K.S.; Yoshimura, S.; Saito, H. Alternating magnetic force microscopy: Effect of Si doping on the temporal performance degradation of amorphous FeCoB magnetic tips. J. Magn. Magn. Mater. 2019, 471, 209-214. [CrossRef]

28. Yamaoka, T.; Watanabe, K.; Shirakawabe, Y.; Chinone, K.; Saitoh, E.; Tanaka, M.; Miyajima, H. Applications of high-resolution MFM system with low-moment probe in a vacuum. IEEE Trans. Magn. 2005, 41, 3733-3735. [CrossRef]

29. Yamaoka, T.; Tsujikawa, H.; Hasumura, S.; Andou, K.; Shigeno, M.; Ito, A.; Kawamura, H. Vacuum magnetic force microscopy at high temperatures: Observation of permanent magnets. Microsc. Today 2014, 22, 12-17. [CrossRef]

30. Suzuki, K.; Katamura, S.; Mooney, C.B. Observation of magnetic film using magnetic force microscope (MFM) in ultra-high vacuum (UHV). Microsc. Microanal. 2001, 7, 866-867. [CrossRef]

31. Akdogan, O.; Akgodan, N.G. SmCo-based MFM probes with high switching fields. J. Magn. Magn. Mater. 2021, $520,167124$. [CrossRef]

32. Thielsch, J.; Stopfel, H.; Wolff, U.; Neu, V.; Woodcock, T.G.; Güth, K.; Schult, L.; Gutfleisch, O. In situ magnetic force microscope studies of magnetization reversal of interaction domains in hot deformed Nd-Fe-B magnets. J. Appl. Phys. 2012, $111,103901$. [CrossRef]

33. Álvarez-Sánchez, R.; García-Martin, J.M.; Briones, F.; Costa-Krämer, J.L. Domain structure and reversal mechanism through diffracted magneto-optics in $\mathrm{Fe}_{80} \mathrm{~B}_{20}$ microsquare arrays. Magnetochemistry 2020, 6, 50. [CrossRef]

34. Ciuta, G.; Dumas-Bouchiat, F.; Dempsey, N.M.; Fruchart, O. Some aspects of magnetic force microscopy of hard magnetic films. IEEE Trans. Magn. 2016, 52, 1-8. [CrossRef] 
35. Skomski, R.; Zeng, H.; Sellmyer, D.J. Incoherent magnetization reversal in nanowires. J. Magn. Magn. Mater. 2002, $249,175-180$. [CrossRef]

36. Cisternas, E.; Faúndez, J.; Vogel, E.E. Stabilization mechanisms for information stored in magnetic nanowire arrays. J. Magn. Magn. Mater. 2017, 426, 588-593. [CrossRef]

37. Sun, L.; Hao, Y.; Chien, C.L.; Searson, P.C. Tuning the properties of magnetic nanowires. IBM J. Res. 2005, 49, 79-102. [CrossRef]

38. Maurer, T.; Ott, F.; Chaboussant, G.; Soumare, Y.; Piquemal, J.Y.; Viau, G. Magnetic nanowires as permanent magnet materials. Appl. Phys. Lett. 2007, 91, 172501. [CrossRef]

39. Li, H.J.; Wu, Q.; Yue, M.; Peng, Y.; Li, Y.P.; Liang, J.M.; Wang, D.J.; Zhang, J.X. Magnetization reversal in cobalt nanowires with combined magneto-crystalline and shape anisotropies. J. Magn. Magn. Mater. 2019, 481, 104-110. [CrossRef]

40. Qin, D.-H.; Zhang, H.-L.; Xu, C.-L.; Xu, T.; Li, H.-L. Magnetic domain structure in small diameter magnetic nanowire arrays. Appl. Surf. Sci. 2005, 239, 279-284. [CrossRef]

41. Qin, D.H.; Lu, M.; Li, H.L. Magnetic force microscopy of magnetic domain structure in highly ordered Co nanowire arrays. Chem. Phys. Lett. 2001, 350, 51-56. [CrossRef]

42. Escrig, J.; Altbir, D.; Jaafar, M.; Navas, D.; Asenjo, A.; Vázques, M. Remanence of Ni nanowire arrays: Influence of size and labyrinth magnetic structure. Phys. Rev. B 2007, 75, 184429. [CrossRef]

43. Yuan, J.F.; Pei, W.; Hasagawa, T.; Washiya, T.; Sait, H.; Ishio, S.; Oshima, H.T.; Itoh, K.-I. Study on magnetization reversal of cobalt nanowire arrays by magnetic force microscopy. J. Magn. Magn. Mater. 2008, 320, 736-741. [CrossRef]

44. Asenjo, A.; Jaafar, M.; Navas, D.; Vázquez, M. Quantitative magnetic force microscopy analysis of the magnetization process in nanowire arrays. J. Appl. Phys. 2006, 100, 023909. [CrossRef]

45. Nielsch, K.; Wehrspohn, R.B.; Barthel, J.; Kirschner, J.; Fischer, S.F.; Kronmüller, H.; Schweinböck, T.; Weiss, D.; Gösele, U. High density hexagonal nickel nanowire array. J. Magn. Magn. Mater. 2002, 249, 234-240. [CrossRef]

46. May, A.; Hunt, M.; Van den Berg, A.; Hejazi, A.; Ladak, S. Realisation of a frustrated 3D magnetic nanowire lattice. Commun. Phys. 2019, 2, 13. [CrossRef]

47. May, A.; Saccone, M.; van den Berg, A.; Askey, J.; Hunt, M.; Ladak, S. Magnetic charge propagation upon a 3D artificial spin-ice. Nat. Comm. 2021, 12, 3217. [CrossRef]

48. Ladak, S.; Read, D.E.; Perkins, G.K.; Cohen, L.F.; Branford, W.R. Direct observation of magnetic monopole defects in an artificial spin-ice system. Nat. Phys. 2010, 6, 359-363. [CrossRef]

49. Rollani, V.; Munoz-Noval, A.; Gomez, A.; Valdes-Bango, M.J.I.; Velez, M.; Osorio, M.R.; Granados, D.; Gonzalez, E.M.; Vicent, J.L. Topologically protected superconducting ratchet effect generated by spin-ice nanomagnets. Nanotechnology 2019, 30, 244003 [CrossRef]

50. Gartside, J.C.; Arroo, D.M.; Burn, D.M.; Bemmer, V.L.; Moskalenko, A.; Cohen, L.F.; Branford, W.R. Realization of ground state in artificial kagome spin ice via topological defect-driven magnetic writing. Nat. Nanotechnol. 2018, 13, 53-58. [CrossRef]

51. Keswani, N.; Lopes, R.J.C.; Nakajima, Y.; Singh, R.; Chauhan, N.; Som, T.; Kumar, D.S.; Pereira, A.R.; Das, P. Controlled createion and annihilation of isolated robust emergent magnetic monopole like charged vertices in square artificial spin ice. Sci. Rep. 2021, 11, 13593. [CrossRef] [PubMed]

52. Talapatra, A.; Singh, N.; Adeyeye, A.O. Magnetic tenability of permalloy artificial spin ice structures. Phys. Rev. Appl. 2020, 13, 014034. [CrossRef]

53. Puttock, R.; Manzin, A.; Neu, V.; Garcia-Sanchez, F.; Fernandez Scarioni, A.; Schumacher, H.W.; Kazakova, O. Modal frustration and periodicity breaking in artificial spin ice. Small 2020, 16, 2003141. [CrossRef] [PubMed]

54. Berganza, E.; Jaarar, M.; Bran, C.; Fernández-Roldán, J.A.; Chubykalo-Fesenko, O.; Vázquez, M.; Asenjo, A. Multisegmented nanowires: A step towards the control of the domain wall configuration. Sci. Rep. 2017, 7, 11576. [CrossRef]

55. Bran, C.; Fernandez-Roldan, J.A.; Palmero, E.M.; Berganza, E.; Guzman, J.; del Real, R.P.; Asenjo, A.; Fraile Rodríguez, A.; Foerster, M.; Aballe, L.; et al. Direct observation of transverse and vortex metastable magnetic domains in cylindrical nanowires. Phys. Rev. B 2017, 96, 125415. [CrossRef]

56. Askey, J.; Hunt, M.O.; Langbein, W.; Ladak, S. Use of two-photon lithography with a negative resist and processing to realize cylindrical magnetic nanowires. Nanomaterials 2020, 10, 429. [CrossRef] [PubMed]

57. Nasirpouri, F.; Nogaret, A.; Bending, S.J. Effect of size and configuration on the magnetization of nickel dot arrays. IEEE Trans. Magn. 2011, 47, 4695-4700. [CrossRef]

58. Nasirpouri, F.; Peighambari-Sattari, S.-M.; Bran, C.; Palmero, E.M.; Berganza Eguiarte, E.; Vazquez, M.; Patsopoulos, A.; Kechrakos, D. Geometrically designed domain wall trap in tri-segmented nickel magnetic nanowires for spintronics devices. Sci. Rep. 2019, 9, 9010. [CrossRef]

59. Corte-León, H.; Rodríguez, L.A.; Pancaldi, M.; Gatel, C.; Cox, D.; Snoeck, E.; Antonov, V.; Vavassori, P.; Kazakova, O. Magnetic imaging using geometrically constrained nano-domain walls. Nanoscale 2019, 11, 4478-4488. [CrossRef]

60. O'Barr, R.; Lederman, M.; Schultz, S.; Xu, W.H.; Scherer, A.; Tonucci, R.J. Preparation and quantitative magnetic studies of single-domain nickel cylinders. J. Appl. Phys. 1996, 79, 5303. [CrossRef]

61. Shin, H.W.; Son, J.Y. Magnetic domain structure and magnetic anisotropy in ferromagnetic $\mathrm{Y}_{3} \mathrm{Fe}_{5} \mathrm{O}_{12}$ nanowires formed by step-edge decoration. J. Magn. Magn. Mater. 2017, 444, 102-105. [CrossRef]

62. Ebels, U.; Radulescu, A.; Henry, Y.; Piraux, L.; Ounadjela, K. Spin accumulation and domain wall magnetoresistance in 35 nm Co wires. Phys. Rev. Lett. 2000, 84, 983-986. [CrossRef] 
63. Henry, Y.; Ounadjela, K.; Piraux, L.; Dubois, S.; George, J.-M.; Duvail, J.-L. Magnetic anisotropy and domain patterns in electrodeposited cobalt nanowires. Eur. Phys. J. 2001, 20, 35-54. [CrossRef]

64. Belliard, L.; Miltat, J.; Thiaville, A.; Dubois, S.; Duvail, J.L.; Piraux, L. Observing magnetic nanowires by means of magnetic force microscopy. J. Magn. Magn. Mater. 1998, 190, 1-16. [CrossRef]

65. García, J.M.; Thiaville, A.; Miltat, J. MFM imaging of nanowires and elongated patterned elements. J. Magn. Magn. Mater. 2002, 249, 163-169. [CrossRef]

66. Bran, C.; Fernandez-Roldan, J.A.; del Real, R.P.; Asenjo, A.; Chubykalo-Fesenko, O.; Vazquez, M. Magnetic configurations in modulated cylindrical nanowires. Nanomaterials 2021, 11, 600. [CrossRef] [PubMed]

67. Bochmann, S.; Döhler, D.; Trapp, B.; Stano, M.; Fruchart, O.; Bachmann, J. Preparation and physical properties of soft magnetic nickel-cobalt three-segmented nanowires. J. Appl. Phys. 2018, 124, 163907. [CrossRef]

68. Bochmann, S.; Fernandez-Pacheco, A.; Mackovic, M.; Neff, A.; Siefermann, K.R.; Spiecker, E.; Cowburn, R.P.; Bachmann, J. Systematic tuning of segmented magnetic nanowires into three-dimensional arrays of 'bits'. RSC Adv. 2017, 7, 37627-37635. [CrossRef]

69. De Campos Pinto Sinnecker, E.H.; García-Martin, J.M.; Altbir, D.; D'Albuquerque e Castro, J.; Sinnecker, J.P. A magnetic force microscopy study of patterned T-shaped structures. Materials 2021, 14, 1567.

70. Blachowicz, T.; Ehrmann, A. Micromagnetic investigation of low-symmetry 3D particles. In IOP Conference Series: Materials Science and Engineering; IOP Publishing: Bristol, UK, 2017; Volume 175, p. 012057.

71. Jaafar, M.; Iglesias-Freire, O.; Serrano-Ramón, L.; Ibarra, M.R.; de Teresa, J.M.; Asenjo, A. Distinguishing magnetic and electrostatic interactions by a Kelvin probe force microscopy-magnetic force microscopy combination. Beilstein J. Nanotechnol. 2011, 2, 552-560. [CrossRef]

72. Zagorskii, D.L.; Doludenko, I.M.; Cherkasov, D.A.; Zhigalina, O.M.; Khmelenin, D.N.; Ivanov, I.M.; Bukharaev, A.A.; Bizyaev, D.A.; Khaibullin, R.I.; Shatalov, S.A. Template synthesis, structure, and magnetic properties of layered nanowires. Phys. Solid State 2019, 61, 1634-1645. [CrossRef]

73. Kodaira, R.; Horiguchi, R.; Hara, S.J. Magnetization characterization of MnAs nanoclusters at close range in bended MnAs/InAs heterojunction nanowires. J. Crystal Growth 2019, 507, 241-245. [CrossRef]

74. Dai, G.L.; Hu, X.K.; Sievers, S.; Scarloni, A.F.; Neu, V.; Fluegge, J.; Schumacher, H.W. Metrological large range magnetic force microscopy. Rev. Sci. Instr. 2018, 89, 093703. [CrossRef]

75. Choopani, S.; Samavat, F.; Kolobova, E.N.; Grishin, A.M. Ferromagnetic resonance and magnetic anisotropy in biocompatible $\mathrm{Y}_{3} \mathrm{Fe}_{5} \mathrm{O}_{12} @ \mathrm{Na}_{0.5} \mathrm{~K}_{0.5} \mathrm{NbO}_{3}$ core-shell nanofibers. Ceram. Int. 2020, 46, 2072-2078. [CrossRef]

76. Cherkasov, D.A.; Panov, D.V.; Doludenko, I.M.; Kanevskiy, V.M.; Muslimov, A.E.; Zagorskiy, D.L.; Biziaev, D.A.; Bukharaev, A.A. Microscopy investigation of conical and layered nanowires. In IOP Conference Series: Materials Science and Engineering; IOP Publishing: Bristol, UK, 2019; Volume 699, p. 012005.

77. Arias, M.; Pantojas, V.M.; Perales, O.; Otano, W. Synthesis and characterization of magnetic diphase $\mathrm{ZnFe}_{2} \mathrm{O}_{4} / \gamma-\mathrm{Fe}_{2} \mathrm{O}_{3}$ electrospun fibers. J. Magn. Magn. Mater. 2011, 323, 2109-2114. [CrossRef] [PubMed]

78. Prashanthi, K.; Thundat, T. In situ study of electrical field-induced magnetization in multiferroic $\mathrm{BiFeO}_{3}$ nanowires. J. Scanning Microsc. 2014, 36, 224-230. [CrossRef]

79. Prashanthi, K.; Shaibani, P.M.; Sohrabi, A.; Natarajan, T.S.; Thundat, T. Nanoscale magnetoelectric coupling in multiferroic BiFeO 3 nanowires. Phys. Stat. Sol. RRL 2012, 6, 244-246. [CrossRef]

80. Baranowska-Korczyc, A.; Reszka, A.; Sobczak, K.; Sikora, B.; Dziawa, P.; Aleszkiewicz, M.; Klopotowski, L.; Paszkowicz, W.; Dluzewski, P.; Kowalski, B.J.; et al. Magnetic Fe doped ZnO nanofibers obtained by electrospinning. J. Sol.-Gel Sci. Technol. 2012, 61, 494-500. [CrossRef]

81. Pullar, R.C.; Bdikin, I.K.; Bhattacharya, A.K. Magnetic properties of randomly oriented $\mathrm{BaM}, \mathrm{SrM} \mathrm{Co}_{2} \mathrm{Y}, \mathrm{Co}_{2} \mathrm{Z}$ and $\mathrm{Co}_{2} \mathrm{~W}$ hexagonal ferrite fibres. J. Eur. Ceram. Soc. 2012, 32, 905-913. [CrossRef]

82. Zheng, J.; Du, K.; Xiao, D.; Zhou, Z.-Y.; Wei, W.-G.; Chen, J.-J.; Yin, L.-F.; Shen, J. Synthesis of ordered ultra-long manganite nanowires via electrospinning method. Chin. Phys. Lett. 2016, 33, 097501. [CrossRef]

83. Sreenivasulu, G.; Popov, M.; Zhang, R.; Sharma, K.; Janes, C.; Mukundan, A.; Srinivasan, G. Magnetic field assisted self-assembly of ferrite-ferroelectric core-shell nanofibers and studies on magneto-electric interactions. Appl. Phys. Lett. 2014, 104, 052910. [CrossRef]

84. Liu, N.N.; Du, P.C.; Zhou, P.; Tanguturi, R.G.; Qi, Y.J.; Zhang, T.J. Magnetoelectric coupling in $\mathrm{CoFe}_{2} \mathrm{O}_{4}-\mathrm{Pb}\left(\mathrm{Zr}_{0.2} \mathrm{Ti}_{0.8}\right) \mathrm{O}_{3} \operatorname{coaxial}$ nanofibers. J. Am. Ceram. Soc. 2021, 104, 948-954. [CrossRef]

85. Sreenivasulu, G.; Zhang, J.T.; Zhang, R.; Popov, M.; Petrov, V.; Srinivasan, G. Multiferroic core-shell nanofibers, assembly in a magnetic field, and studies on magneto-electric interaction. Materials 2018, 11, 18. [CrossRef]

86. Prasad, P.D.; Hemalatha, J. Multifunctional films of poly(vinylidene fluoride) $/ \mathrm{ZnFe}{ }_{2} \mathrm{O}_{4}$ nanofibers for nanogenerator applications. J. Alloys Compd. 2021, 854, 157189. [CrossRef]

87. Saito, H.; Ikeya, H.; Egawa, G.; Ishio, S.; Yoshimura, S. Magnetic force microscopy of alternating magnetic field gradient by frequency modulation of tip oscillation. J. Appl. Phys. 2009, 105, 07D524. [CrossRef]

88. Saito, H.; Ito, R.; Egawa, G.; Li, Z.; Yoshimura, S. Direction detectable static magnetic field imaging by frequency-modulated magnetic force microscopy with an AC magnetic field driven soft magnetic tip. J. Appl. Phys. 2011, 109, 07E330. [CrossRef] 
89. Cao, Y.Z.; Zhao, Y.; Kumar, P.; Yoshimura, S.; Saito, H. Magnetic domain imaging of a very rough fractured surface of Sr ferrite magnet without topographic crosstalk by alternating magnetic force microscopy with a sensitive FeCo-GdO $\mathrm{F}_{\mathrm{x}}$ superparamagnetic tip. J. Appl. Phys. 2018, 123, 224503. [CrossRef]

90. Fewell, M.P.; Mitchell, D.R.G.; Priest, J.M.; Short, K.T.; Collins, G.A. The nature of expanded austenite. Surf. Coat. Technol. 2000, 131, 300-306. [CrossRef]

91. Öztürk, O.; Okur, S.; Riviere, J.P. Structural and magnetic characterization of plasma ion nitrided layer on 316L stainless steel alloy. Nucl. Instrum. Methods Phys. Res. Sect. B Beam Interact. Mater. At. 2009, 267, 1540-1545. [CrossRef]

92. Kamble, S.S.; Sikora, A.; Pawar, S.T.; Maldar, N.N.; Deshmukh, P.P. Cobalt sulfide thin films: Chemical growth, reaction kinetics and microstructural analysis. J. Alloys Compd. 2015, 623, 466-472. [CrossRef]

93. Jena, A.K.; Arout Chelvane, J.; Mohanty, J. Simultaneous improvement of piezoelectric and magnetic properties in diamagnetic ion modified $\mathrm{BiFeO}_{3}$ film. J. Alloys Compd. 2019, 805, 1168-1174. [CrossRef]

94. Sharma, A.; Tripathi, S.; Ugochukwu, K.C.; Tripathi, J. Magnetic and structural properties of Ni nanocaps deposited onto self assembled nanosphere array. Thin Solid Films 2013, 536, 249-255. [CrossRef]

95. Nenadovic, M.; Strbac, S.; Rakocevic, Z. Quantification of the lift height for magnetic force microscopy using 3D surface parameters. Appl. Surf. Sci. 2010, 256, 1652-1656. [CrossRef] 